\title{
Reducing Young Adults' Health Care Spending through the ACA Expansion of Dependent Coverage
}

\author{
Jie Chen, Arturo Vargas-Bustamante, and Priscilla Novak
}

Objective. To estimate health care expenditure trends among young adults ages 1925 before and after the 2010 implementation of the Affordable Care Act (ACA) provision that extended eligibility for dependent private health insurance coverage.

Data Sources. Nationally representative Medical Expenditure Panel Survey data from 2008 to 2012.

Study Design. We conducted repeated cross-sectional analyses and employed a difference-in-differences quantile regression model to estimate health care expenditure trends among young adults ages 19-25 (the treatment group) and ages 27-29 (the control group).

Principal Findings. Our results show that the treatment group had 14 percent lower overall health care expenditures and 21 percent lower out-of-pocket payments compared with the control group in 2011-2012. The overall reduction in health care expenditures among young adults ages 19-25 in years 2011-2012 was more significant at the higher end of the health care expenditure distribution. Young adults ages 19-25 had significantly higher emergency department costs at the 10th percentile in 2011-2012. Differences in the trends of costs of private health insurance and doctor visits are not statistically significant.

Conclusions. Increased health insurance enrollment as a consequence of the ACA provision for dependent coverage has successfully reduced spending and catastrophic expenditures, providing financial protections for young adults.

Key Words. Health care expenditures, young adults, the Affordable Care Act

The Affordable Care Act (ACA) extended eligibility for dependent coverage under private family health insurance up to age 26 (Kaiser Family Foundation 2013). This provision allowed young adults to remain insured under their parents' private health insurance plan until age 26. Extended eligibility for dependent coverage was one of the earliest ACA provisions to be implemented, coming into force on September 23, 2010. Recent estimates show that this provision has reduced the number of uninsured young adults by an 
absolute number of at least 3 million individuals (Kaiser Commission on Medicaid and the Uninsured 2014). In percentage terms, in 2013, among young adults ages 19-25, 22.9 percent were uninsured for the entire year. This is lower than for the same population in 2009 , when 27.5 percent were uninsured for the entire year (Rhoades 2015).

The population between ages 19 and 30 was labeled by the media and government institutions as "young invincibles" (Smith 2009), because of their belief that young adults were healthy enough to be uninsured without major consequences. Before the implementation of the ACA, approximately 30 percent of young adults were uninsured, representing approximately one in five uninsured individuals in the United States (Centers for Medicare \& Medicaid Services 2010). Young adults experienced the highest uninsured rate compared with older adults and children, primarily because young adults experienced the lowest amount of employer-provided coverage (Centers for Medicare \& Medicaid Services 2010). Young adults were frequently employed in entry and part-time positions, which were less likely to offer employer sponsored health insurance (Merluzzi and Nairn 1999; Callahan and Cooper 2005).

Different ACA-related strategies aimed to increase coverage among young adults, by expanding Medicaid coverage, creating health insurance exchanges, and extending private health insurance dependent coverage eligibility from age 19 to age 26 (Claxton, Rae, and Panchal 2013; Mulcahy et al. 2013; Sommers et al. 2013; Busch, Golberstein, and Meara 2014; Chua and Sommers 2014). Collectively, these strategies offered young adults a smoother transition to their own health insurance coverage. According to Cantor et al. $(2012 \mathrm{a}, \mathrm{b})$, the "ACA-dependent coverage expansion represents a rare public policy success in the effort to cover the uninsured."

Our study focuses on health care expenditure trends among young adults before and after the extension of dependent coverage eligibility. Chua and Sommers (2014) examined total health care costs and out-of-pocket (OOP) payments among young adults. Their results showed significant reduction in OOP expenditures in 2011, but found no changes in overall health care expenditures from 2002 to 2011 . These results may be sensitive to the short time period after the ACA expansion. The association between the ACA expansion and health

Address correspondence to Jie Chen, Ph.D., Department of Health Services and Administration, School of Public Health, University of Maryland-College Park, 3310E, College Park, MD 20742; e-mail: jichen@umd.edu. Arturo Vargas-Bustamante, Ph.D., is with the Department of Health Policy and Management, Fielding School of Public Health, University of California, Los Angeles, CA. Priscilla Novak, M.P.H., is with the Department of Health Services and Administration, School of Public Health, University of Maryland-College Park, College Park, MD. 
care expenditures might also differ along the distribution of health care expenditures (Cook and Manning 2009; Chen et al. 2014). Higher health care expenditure may indicate higher intensity of care, such as cancer treatment, and lower health care expenditures may indicate demand for primary health care services (e.g., prescription drug use and physician visits) (Cook and Manning 2009; Chen et al. 2014). Since this ACA provision expanded insurance coverage, beneficiaries of this provision, those young adults ages 19-25, would have better access to primary care, and potentially reduce their emergency department (ED) utilization. In other words, we may observe the ACA provision is positively associated with the lower end of the health expenditures distribution (e.g., spending on primary care) and negatively associated with the higher end of this distribution (e.g., spending on ED visits).

In this study, we use quantile regression with difference-in-differences estimates to identify changes along the health expenditures distribution (Chen et al. 2014). We implement before and after comparisons of health care services used by young adults to identify any changes in health care spending patterns as a consequence of the dependent coverage expansion up to age 26. In addition, it is likely that the cost shifting among different types of health insurance plans might have happened during this transition. Hence, we also examine the pattern of health care spending across payers. Young adults' health spending patterns are expected to impact aggregate U.S. health spending in the long term. Lack of health care access and health insurance may result in delaying or forgoing necessary treatment, potentially leading to health problems and higher health expenditures in midadulthood (Merluzzi and Nairn 1999; Callahan and Cooper 2005). Our study provides first evidence on the changes of health spending patterns under this ACA provision.

\section{METHOD}

\section{Data}

We use nationally representative data from the 2008 to 2012 Medical Expenditure Panel Survey (MEPS) (Cohen, Cohen, and Banthin 2009). MEPS is a nationally representative survey of the civilian, noninstitutionalized population in the United States. It provides respondents' detailed health care spending during the survey year, as well as their demographics, socioeconomic characteristics, health status, and health insurance status. 
Our outcome variables are annual health care expenditures per person, including total health care spending and spending on specific types of health care services (e.g., costs of physician visits). We also examine expenditures by payers, such as patients (i.e., OOP payments), private insurers, and public payers. Health care expenditures are self-reported and validated by respondents' physicians and pharmacists. All health expenditures are adjusted to constant U.S. dollars using the 2012 Consumer Price Index Medical Component.

We parse the U.S. young adult population into two groups: the ACAdependent coverage expansion targeted group (adults ages 19-25) and nontargeted group (those who were 27-29 years old). To be consistent with previous studies, we also use young adults 27-29 years old as the reference group (Busch, Golberstein, and Meara 2014; Barbaresco, Courtemanche, and Qi 2015; Golberstein et al. 2015). We exclude 26-year-old individuals due to the lack of accurate information to determine their eligibility when the ACA was implemented in 2010. Under the ACA, since September 23, 2010, young adults were able to join or remain on their parents' private health insurance plan, regardless of marital status, school attendance, financial dependence on parents, or eligibility for employer-provided health insurance coverage (U.S. Department of Labor 2014). Some large employers claim that they expanded coverage in early 2010. To capture a precise snapshot of health care expenditures due to the ACA expansion, we use 2008-2009 and 2011-2012 as the pre- and post-implementation period.

The sample size of young adults ages 19-25 and 27-29 in 2008-2009 and 2011-2012 is 12,564 . A total of 11,154 observations remained after dropping the observations with missing variables. We further exclude 15 outliers with expenditure higher than 3 standard deviations above the average expenditure. Our final sample has 7,623 young adults 19-25 years old and 3,516 young adults 27-29 years old.

\section{Analysis}

We first summarize overall and specific health care expenditures for young adults ages 19-25 and ages 27-29 in 2008-2009 (before the ACA expansion) and 2011-2012 (after the ACA expansion of young adults' health insurance coverage was fully implemented). We then compare population characteristics between these two groups, with individuals ages 27-29 as the reference group. The survey weights were employed to adjust sample characteristics to be nationally representative. To capture this natural experiment of health 
insurance eligibility among young adults, we use a difference-in-differences approach to identify any changes in health care expenditures among the targeted population (young adults ages 19-25 years old) in the pre- (20082009) and the post- (2011-2012) implementation periods, relative to changes in health care expenditures of the nontargeted comparison group (adults ages 27-29 years old).

Difference-in-differences method assumes "parallel trends" (Wooldridge 2002; Dimick and Ryan 2014) in outcomes between the treatment and comparison groups prior to the intervention, which is the ACA expansion in our study. To test whether the trends of health care expenditures are parallel before the intervention, we use data from earlier years of the MEPS and construct the interaction terms between the treatment group "young adults ages 19-25" with each survey year. We test the significance of these interaction terms for all outcome variables, which are total health care expenditures, OOP payment, private health insurance expenditures, Medicaid expenditures; and costs of doctor visits, prescription drugs, ED visits and inpatient visits. Results (Appendices SA2 and SA3) show that most of the interaction terms are statistically insignificant which indicate that health expenditure trends between young adults ages 19-25 and young adults ages 27-29 are parallel pre-ACA. These findings justify the use of adults ages 2729 as our treatment group.

Importantly, the interaction terms in the regressions of Medicaid expenditure (year 2004 and year 2008), prescription drug cost (year 2006), and inpatient visit costs (in multiple years) were statistically significant $(p<.05)$. This finding may suggest that young adults ages $27-29$ are not the comparable treatment group to examine these outcomes. Thus, we exclude the analyses on Medicaid expenditures, prescription drug costs, and inpatient visit costs.

Hence, our outcome variables are total health care expenditures, OOP, cost paid by private health insurers, and costs of ED and doctor visits. We use a repeated cross-sectional study design and apply a generalized linear model with log link and gamma distribution (GLM) to estimate health care expenditures. The model specification for the difference-in-differences analysis is presented in the following equation.

Health care expenditures $=\beta_{0}+\beta_{1}($ Age $19-25)+\beta_{2}($ Years $2011-2012)$

$$
\begin{aligned}
& +\beta_{3}(\text { Age } 19-25 * \text { Years } 2011-2012) \\
& +\beta_{4}(\text { covariates })+\varepsilon
\end{aligned}
$$


We use the conceptual framework of Andersen social behavioral model (Aday and Andersen 1974; Andersen 1995) to select the covariates that are associated with health care expenditures. The covariates included in our study can be categorized into three domains: the predisposing factors (race/ethnicity, gender, marital status, U.S. born vs. foreign born, and interview language) (Chen, Vargas-Bustamante, and Ortega 2013); enabling factors (education, family income, urban/rural, and U.S. Census Region); and clinical needs factors (self-reported physical and mental health, SF12-physical component summary (PCS), and mental component summary (MCS) (Ware, Kosinski, and Keller 1996). These variables have been widely used in the literature to examine health care expenditures and utilization (Cook and Manning 2009; Ku 2009; Chen et al. 2014).

Prior research suggests that health care expenditures are highly concentrated and not evenly distributed, with only 5 percent of the U.S. population accounting for half of health care expenditures (Staton 2006), while approximately 50 percent of the population has minimal expenditure on health care. GLM estimation takes into account the skewed health care expenditures distribution, addresses heterogeneities, and provides consistent and efficient estimates (Goldberger 1964; Wooldridge 2002; Manning, Basu, and Mullahy 2005). All our results are nationally representative using the survey weights provided by the MEPS. Stata $12 \mathrm{MP}$ was used to conduct the analysis.

Health care spending may be indicative of consumers' different health needs (Cook and Manning 2009; Chen et al. 2014). Thus, in this study, we use the quantile regression model to examine whether the effects of the ACA's expansion on young adults' coverage eligibility vary along the health expenditure distributions (Koenker and Hallock 2001; Koenker 2005). The coefficients at the lower percentiles of the health expenditure distributions (e.g., the 10th, 25th, and 50th percentiles) reflect the associations between the ACA expansion and health expenditures on primary or routine health care. The coefficients at the higher percentiles of health expenditures (e.g., the 75th, 90th, and 95th percentiles) indicate the associations between the ACA expansion and the use of more intense and costly health care services (Chen et al. 2014).

\section{RESULTS}

Figure 1 presents the total amount of health care expenditures by payers and services for young adults ages 19-25 and ages 27-29. Compared to adults ages 
Figure 1: Health Care Expenditures for Young Adults Ages 19-25 and Ages 27-29 before and after the ACA Expansion [Color figure can be viewed at wileyonlinelibrary.com]

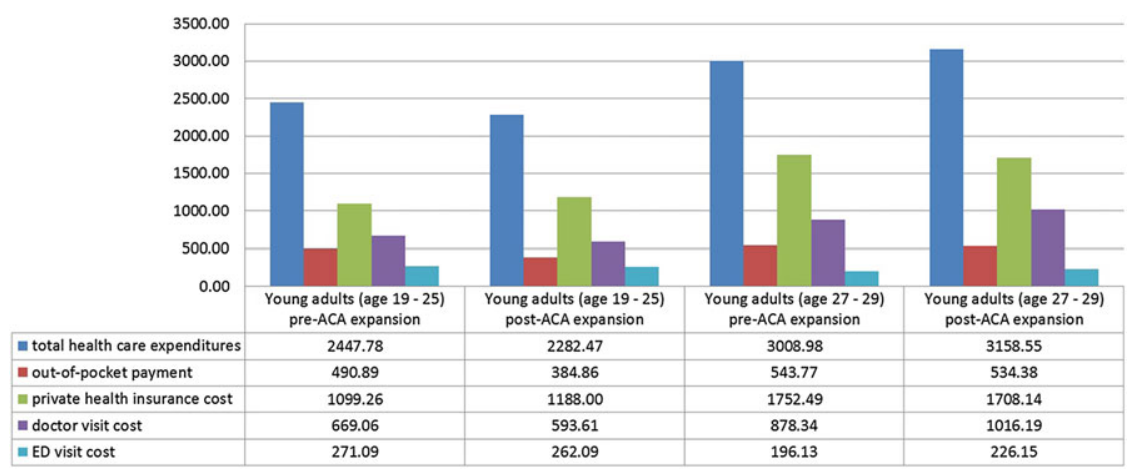

Notes. Dataset: Medical Expenditure Panel Survey 2008-2009, 2011-2012. Results are nationally representative.

27-29 years old, the younger cohort had relatively lower total health care expenditures, OOP, private health insurance expenditures, doctor visit expenditures, but higher ED costs. These expenditures were relatively lower or similar post-ACA expansion. However, among adults 27-29 years old, total health care expenditures and ED visit costs increased post-ACA expansion of dependent coverage.

Table 1 shows population characteristics for our treatment and comparison groups before and after the ACA change in private health insurance eligibility. Adults 19-25 years old were less likely to be married, to report over 12 years of schooling, to be employed, or to report a high family income. The treatment and comparison groups had similar rates of chronic conditions.

Table 2 presents the results of GLM regressions of overall health care expenditures and disaggregates expenditures by payers and services. Results show that after controlling for socioeconomic and demographic factors, the associations between the year indictors (2011-2012) and total health care expenditures and expenditures by payer and services were not statistically significant. Young adults 19-25 years old had comparable total expenditures compared with the control group. In 2011-2012, however, total costs were reduced by 14 percent $(=0.06$ (the coefficient of "Age 19-25")- 0.20 (the coefficient of the interaction term)), and OOP costs were reduced by 21 percent $(=0.08$ (the coefficient of "Age 19-25")-0.29 (the coefficient of the interaction 
Table 1: Population Characteristics of Young Adults Ages 19-25 Years Old and Ages 27-29 Years Old

\begin{tabular}{|c|c|c|c|c|}
\hline & $\begin{array}{c}\text { Age 19-25 } \\
(2008-2009), \\
\text { mean }\end{array}$ & $\begin{array}{c}\text { Age 19-25 } \\
\text { (2010-2012), } \\
\text { mean }\end{array}$ & $\begin{array}{c}\text { Age 27-29 } \\
(2008-2009), \\
\text { mean }\end{array}$ & $\begin{array}{c}\text { Age } 27-29 \\
(2010-2012), \\
\text { mean }\end{array}$ \\
\hline \multicolumn{5}{|l|}{ Race/ethnicity } \\
\hline White & 0.67 & 0.65 & 0.69 & 0.65 \\
\hline Latinos & 0.16 & 0.17 & 0.15 & 0.18 \\
\hline African Americans & 0.12 & 0.13 & 0.11 & $0.11^{*}$ \\
\hline Other races & 0.05 & 0.05 & 0.05 & 0.07 \\
\hline \multicolumn{5}{|l|}{ Gender } \\
\hline Female & 0.54 & 0.56 & $0.58^{*}$ & 0.56 \\
\hline \multicolumn{5}{|l|}{ Marital status } \\
\hline Married & 0.10 & 0.09 & $0.42^{* * * *}$ & $0.37^{* * *}$ \\
\hline \multicolumn{5}{|l|}{ Interviewed English } \\
\hline English & 0.93 & 0.94 & 0.93 & 0.94 \\
\hline \multicolumn{5}{|l|}{ Education } \\
\hline Schooling years $<12$ years & 0.56 & 0.49 & $0.37^{* * *}$ & $0.31^{* * *}$ \\
\hline Schooling years $12-16$ years & 0.42 & 0.49 & $0.53^{* * *}$ & $0.57^{* * *}$ \\
\hline Schooling years $>16$ years & 0.02 & 0.01 & $0.10^{* * *}$ & $0.12^{* * *}$ \\
\hline \multicolumn{5}{|l|}{ Family income } \\
\hline Under 100\% FPL & 0.19 & 0.21 & $0.13^{* * *}$ & $0.14^{* * *}$ \\
\hline $200-400 \%$ FPL & 0.20 & 0.22 & 0.20 & $0.19^{* * *}$ \\
\hline Over $400 \%$ FPL & 0.60 & 0.56 & $0.67^{* * *}$ & $0.67^{* * *}$ \\
\hline Unemployed & 0.19 & 0.22 & $0.13^{* * *}$ & $0.12^{* * *}$ \\
\hline Urban & 0.84 & 0.85 & $0.88^{*}$ & 0.84 \\
\hline \multicolumn{5}{|l|}{ U.S. Census Region } \\
\hline Northeast & 0.16 & 0.18 & 0.18 & 0.16 \\
\hline Midwest & 0.25 & 0.23 & 0.22 & 0.27 \\
\hline South & 0.36 & 0.36 & 0.35 & 0.33 \\
\hline West & 0.24 & 0.23 & 0.25 & $0.25^{*}$ \\
\hline \multicolumn{5}{|l|}{ Self-reported health status } \\
\hline Health poor or fair & 0.08 & 0.06 & 0.08 & 0.08 \\
\hline Health good & 0.21 & 0.21 & $0.25^{*}$ & 0.25 \\
\hline $\begin{array}{l}\text { Health very good or } \\
\text { excellent }\end{array}$ & 0.70 & 0.72 & 0.68 & $0.68^{*}$ \\
\hline \multicolumn{5}{|l|}{ Self-reported mental health status } \\
\hline Mental health poor or fair & 0.06 & 0.05 & 0.05 & 0.05 \\
\hline Mental health good & 0.17 & 0.19 & 0.20 & 0.18 \\
\hline $\begin{array}{l}\text { Mental health very good } \\
\text { or excellent }\end{array}$ & 0.77 & 0.76 & 0.75 & 0.77 \\
\hline SF12-PCS & 0.54 & 0.54 & 0.54 & $0.53^{*}$ \\
\hline SF12-MCS & 0.50 & 0.51 & 0.49 & $0.50 *$ \\
\hline Diabetes & 0.01 & 0.01 & 0.02 & $0.02 *$ \\
\hline Asthma & 0.07 & 0.07 & 0.06 & 0.06 \\
\hline
\end{tabular}


Table 1: Continued

\begin{tabular}{lcccc}
\hline & $\begin{array}{c}\text { Age 19-25 } \\
(2008-2009), \\
\text { mean }\end{array}$ & $\begin{array}{c}\text { Age 19-25 } \\
(2010-2012), \\
\text { mean }\end{array}$ & $\begin{array}{c}\text { Age 27-29 } \\
\text { (2008-2009), } \\
\text { mean }\end{array}$ & $\begin{array}{c}\text { Age 27-29 } \\
\text { (2010-2012), } \\
\text { mean }\end{array}$ \\
\hline Heart disease & 0.01 & 0.01 & 0.00 & 0.00 \\
Depress & 0.07 & 0.07 & 0.08 & 0.09 \\
Anxiety & 0.06 & 0.07 & 0.07 & $0.09^{*}$ \\
\hline
\end{tabular}

Notes. $* * * p<.001 ; * * p<.01 ; * p<.05$, the reference group is young adults ages $19-25$ years old in the same time period. Authors' analysis using the Medical Expenditure Panel Survey 20082009, 2011-2012. Results are nationally representative.

term)) among young adults 19-25 years old, compared with the cost of young adults 27-29 years old.

In addition, Table 2 also shows that among young adults, being a racial or ethnic minority (compared with whites) or male (compared with female) was associated with lower total health care expenditures, OOP, private health insurance expenditures, and lower spending on doctor visits. Individuals speaking English were more likely to have higher total cost, greater private health insurance expenditures, and higher expenditures on doctor visits. Individuals who lived in the South were more likely to have higher OOP, lower spending on doctor visits, but higher ED spending.

Table 3 presents the quantile regression analyses (10th, 25th, 50th, 75th, 90th, and 95th percentiles) of health care expenditures by payer (we present the key findings in Table 3; full sets of results are included in the Appendices). The quantile regressions show that the coefficients for the year indicator 2011-2012 are significantly negative at the lower end (coef $=-0.3, p<.05$ at 25 th percentile; and coef $=-0.16, p<.05$, at 50th percentile) of the distribution of total health care expenditures. The interaction terms between treatment group and year indicator show that at the 90th percentile, the treatment group reported 30 percent lower total cost compared with the control group in 2011-2012 (30 percent $=0.01$ (the coefficient of "age 19-25")-0.31 (the coefficient of the interaction term)).

Quantile regressions in Table 3 show that OOP costs were significantly lower in year 2011-2012 at the 25th and 75th percentiles. OOP costs of the treatment group were reduced significantly at the 90th (the reduction reached 16 percent, $p<.05$ ) and 95th percentiles (the reduction reached 31 percent), compared with the OOP of the control group. Overall costs for private health insurance were similar between the treatment and comparison groups. 


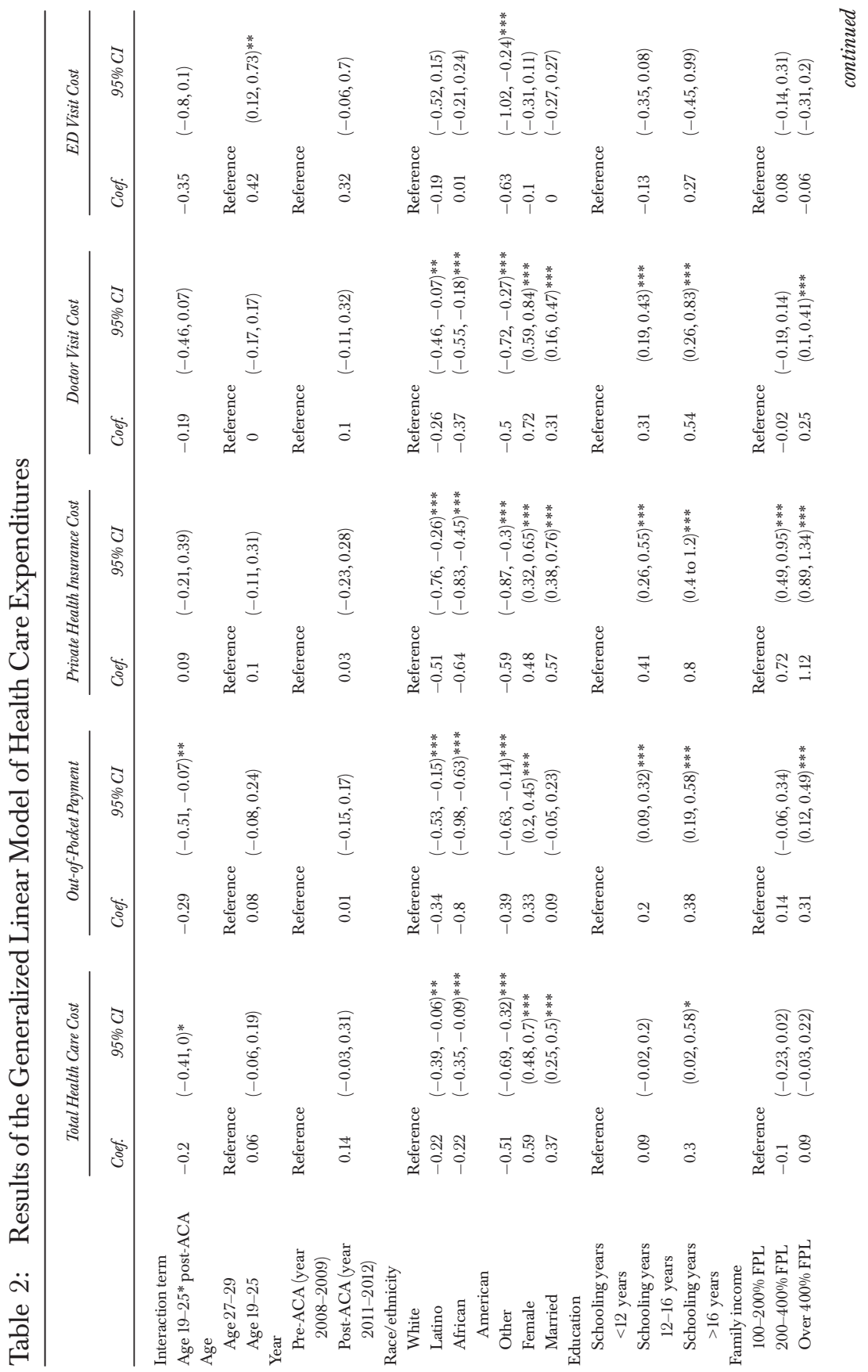




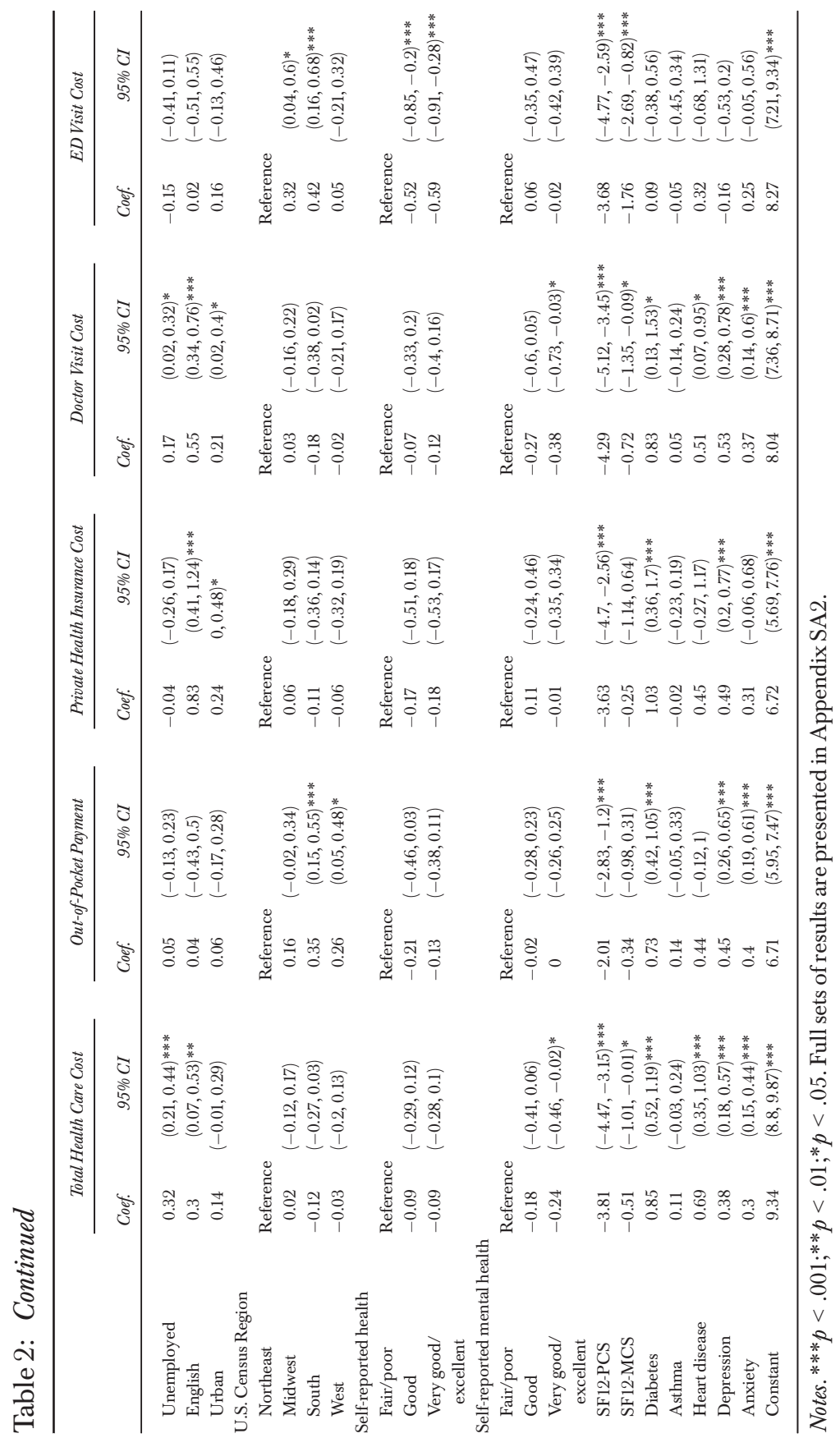




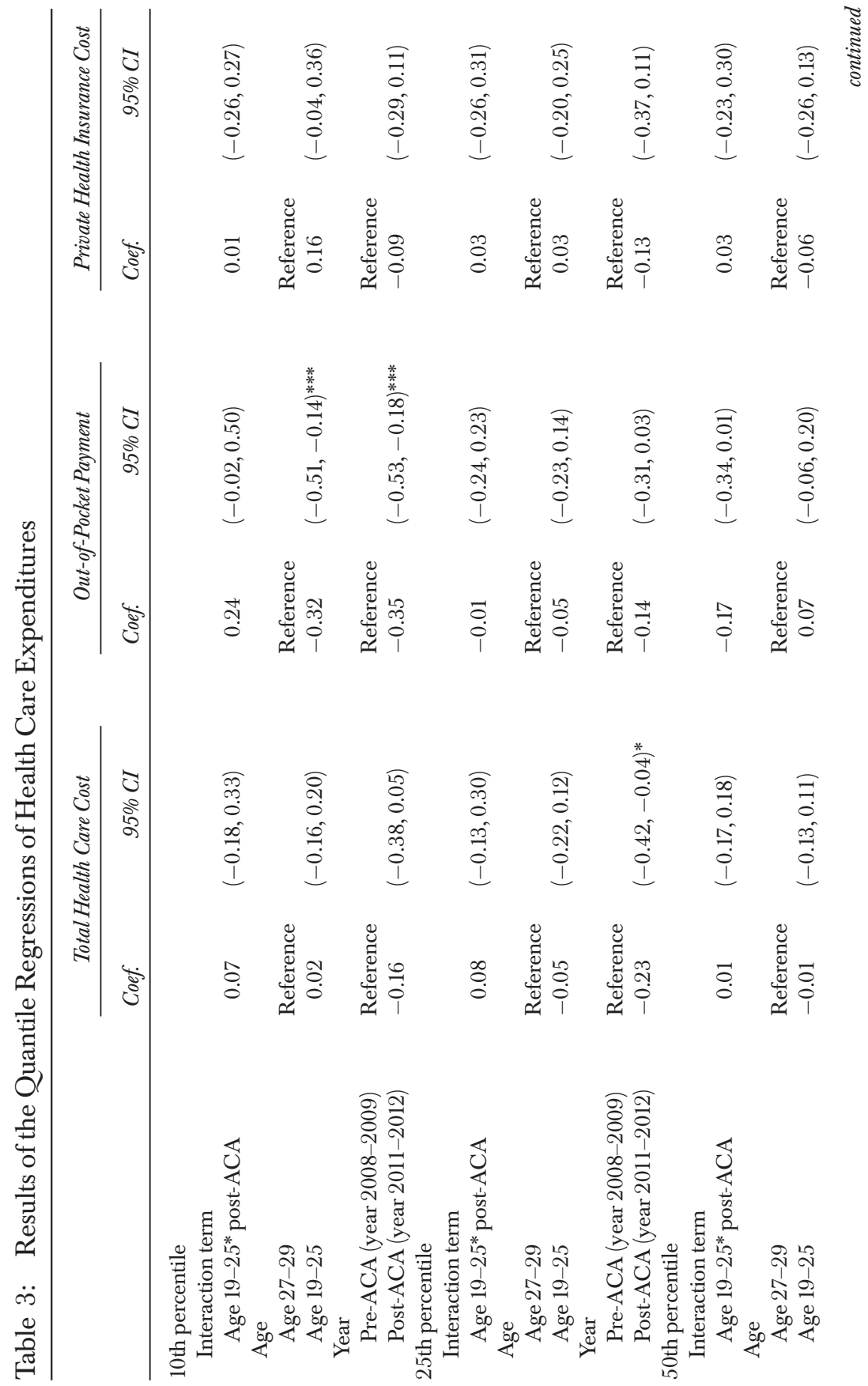




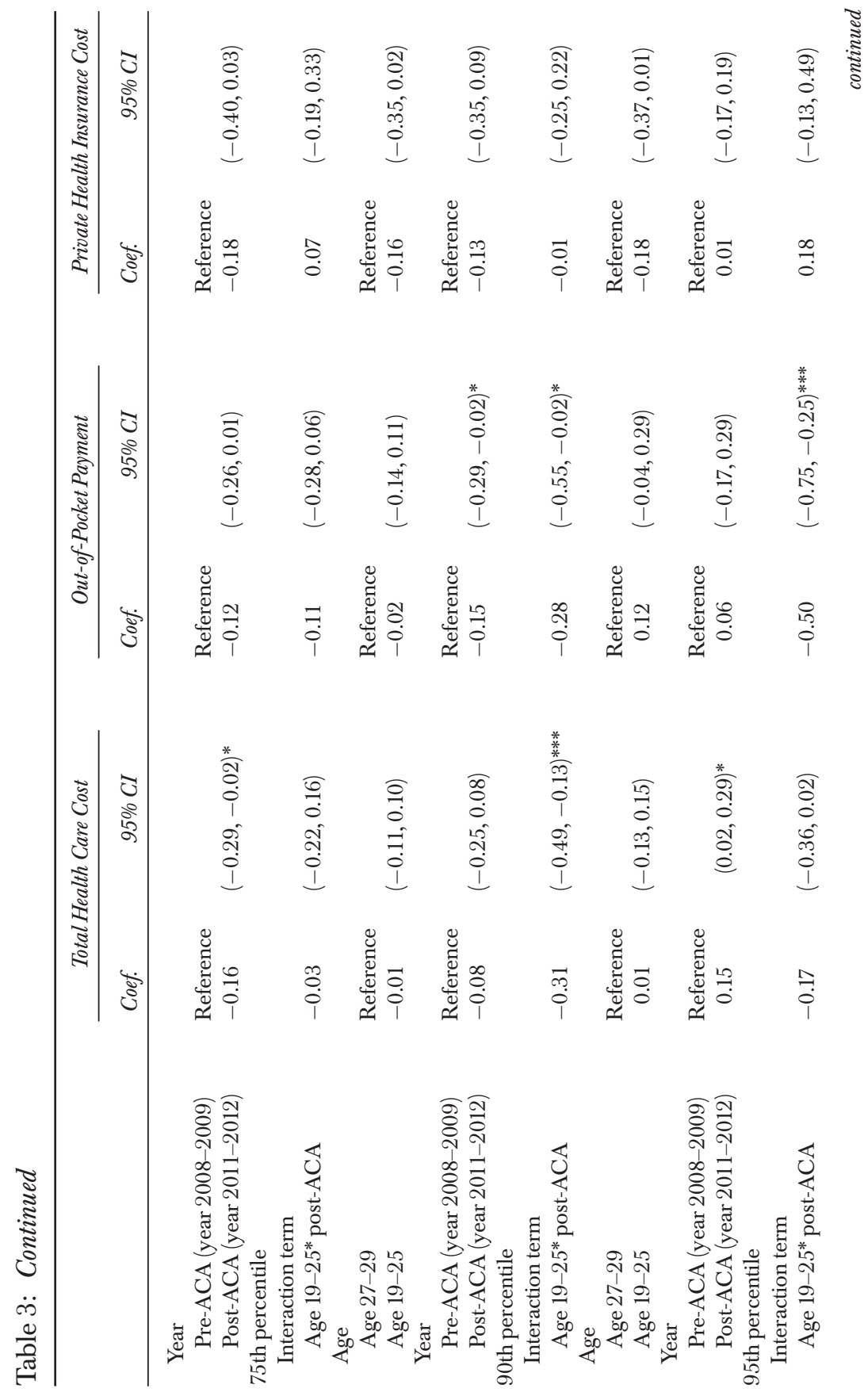




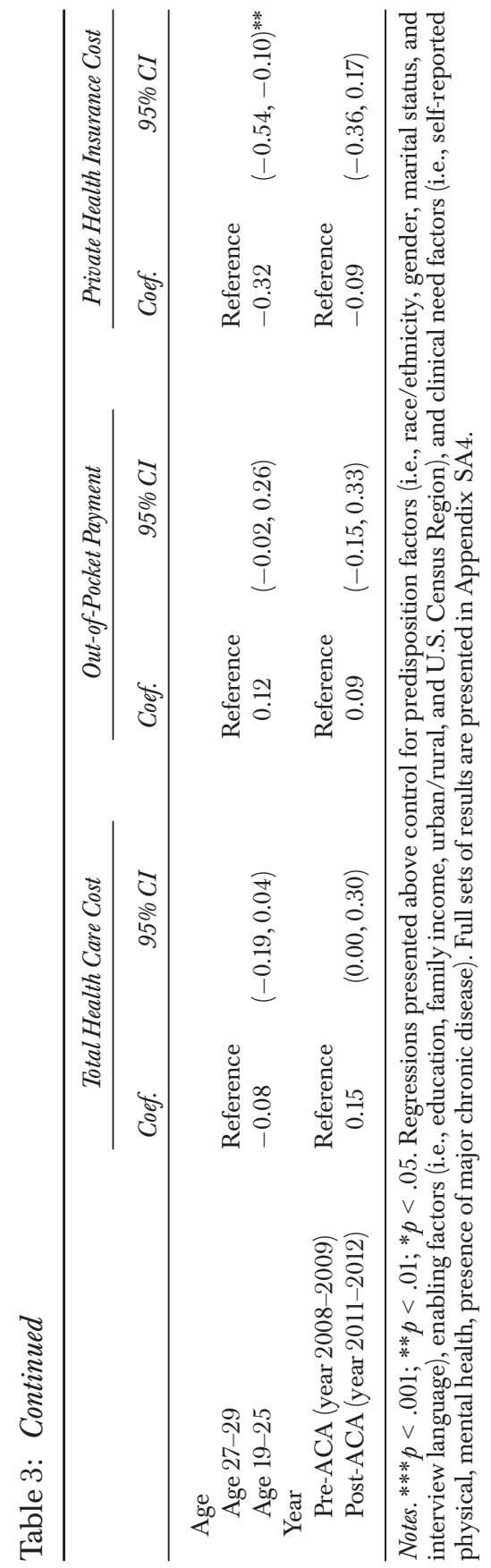


Table 4 presents the results of health care expenditures by types of services. Results show that the treatment group had similar physician costs compared with the control group before and after the ACA's expansion of dependent coverage, along the cost distribution. ED costs were similar between the treatment and control groups and were significantly lower in 2011-2012 for both groups at the 25th percentile but higher at the 90th percentile. We observe that the treatment group had 66 percent higher ED costs compared with the control group in 2011-2012 at the 10th percentile, and no significantly higher ED costs in 2011-2012 at other levels of percentiles.

In sum, our results show that the treatment group (those eligible to join or remain on their parents' private health insurance plan as dependents, i.e., young adults 19-25 years old) had 14 percent lower overall health care expenditures and 21 percent lower OOP costs compared with the comparison group (young adults 27-29 years old) in 2011-2012. Results of the quantile regression suggest that the overall reduction in health care expenditures among young adults ages 19-25 in year 2011-2012 was more significant at the higher end of the health care expenditure distribution. Our findings also indicate that total health care expenditures declined more among the treatment group after the ACA's expansion of dependent eligibility. Similarly, the reduction in OOP among young adults ages 19-25 in years 2011-2012 was more significant at the higher end of the health care expenditure distribution. Results also show that young adults ages 19-25 had significantly higher ED costs compared with young adults ages $27-29$ in 2011-2012 at the 10th percentile, but no significantly higher ED costs in 2011-2012 at other levels of percentiles. We have not observed differences in trends among the costs of private health insurance and doctor visits.

\section{Sensitivity Analyses}

We implement sensitivity analyses to check the robustness of our main findings and of our treatment and comparison categories. The first test excludes full-time students ages 19-23 years from the treatment group since they were already eligible to enroll in their parents' private health insurance before the ACA eligibility shift for young adults. A second test includes young adults ages 26 years old. In addition, we test alternative definitions of outliers and estimate alternative specifications using bootstrapped standard errors in difference-in-differences models (Bertrand, Duflo, and Mullainathan 2004). Our main findings hold to these alternative measures and model specifications. 
Table 4: Results of the Quantile Regressions of Health Care Expenditures by Services

\begin{tabular}{|c|c|c|c|c|}
\hline & \multicolumn{2}{|c|}{ Doctor Visit Cost } & \multicolumn{2}{|c|}{ ED Visit Cost } \\
\hline & Coef. & $95 \% C I$ & Coef. & $95 \% C I$ \\
\hline \multicolumn{5}{|l|}{ 10th percentile } \\
\hline \multicolumn{5}{|l|}{ Interaction term } \\
\hline Age $19-25^{*}$ post-ACA & -0.09 & $(-0.26,0.07)$ & 0.88 & $(0.43,1.32)^{* * *}$ \\
\hline \multicolumn{5}{|l|}{ Age } \\
\hline Age 27-29 & Reference & & Reference & \\
\hline Age 19-25 & 0.05 & $(-0.07,0.18)$ & -0.22 & $(-0.57,0.12)$ \\
\hline \multicolumn{5}{|l|}{ Year } \\
\hline Pre-ACA (year 2008-2009) & Reference & & Reference & \\
\hline Post-ACA (year 2011-2012) & 0.01 & $(-0.14,0.16)$ & -0.60 & $(-0.98,-0.22)^{* * *}$ \\
\hline \multicolumn{5}{|l|}{25 th percentile } \\
\hline \multicolumn{5}{|l|}{ Interaction term } \\
\hline Age $19-25^{*}$ post-ACA & 0.03 & $(-0.15,0.21)$ & 0.25 & $(-0.17,0.67)$ \\
\hline \multicolumn{5}{|l|}{ Age } \\
\hline Age 27-29 & Reference & & Reference & \\
\hline Age 19-25 & 0.00 & $(-0.14,0.14)$ & 0.04 & $(-0.20,0.27)$ \\
\hline \multicolumn{5}{|l|}{ Year } \\
\hline Pre-ACA (year 2008-2009) & Reference & & Reference & \\
\hline Post-ACA (year 2011-2012) & -0.04 & $(-0.20,0.11)$ & -0.26 & $(-0.60,0.07)$ \\
\hline \multicolumn{5}{|l|}{ 50th percentile } \\
\hline \multicolumn{5}{|l|}{ Interaction term } \\
\hline Age $19-25^{*}$ post-ACA & -0.06 & $(-0.24,0.12)$ & -0.04 & $(-0.33,0.26)$ \\
\hline \multicolumn{5}{|l|}{ Age } \\
\hline Age 27-29 & Reference & & Reference & \\
\hline Age 19-25 & -0.01 & $(-0.15,0.13)$ & 0.05 & $(-0.18,0.28)$ \\
\hline \multicolumn{5}{|l|}{ Year } \\
\hline Pre-ACA (year 2008-2009) & Reference & & Reference & \\
\hline Post-ACA (year 2011-2012) & -0.03 & $(-0.18,0.11)$ & -0.07 & $(-0.31,0.17)$ \\
\hline \multicolumn{5}{|l|}{ 75th percentile } \\
\hline \multicolumn{5}{|l|}{ Interaction term } \\
\hline Age $19-25^{*}$ post-ACA & 0.00 & $(-0.20,0.20)$ & -0.14 & $(-0.46,0.17)$ \\
\hline \multicolumn{5}{|l|}{ Age } \\
\hline Age 27-29 & Reference & & Reference & \\
\hline Age 19-25 & -0.11 & $(-0.25,0.04)$ & 0.13 & $(-0.04,0.30)$ \\
\hline \multicolumn{5}{|l|}{ Year } \\
\hline Pre-ACA (year 2008-2009) & Reference & & Reference & \\
\hline Post-ACA (year 2011-2012) & -0.07 & $(-0.24,0.09)$ & 0.10 & $(-0.18,0.37)$ \\
\hline \multicolumn{5}{|l|}{ 90th percentile } \\
\hline \multicolumn{5}{|l|}{ Interaction term } \\
\hline Age $19-25^{*}$ post-ACA & -0.13 & $(-0.36,0.09)$ & -0.23 & $(-0.51,0.05)$ \\
\hline \multicolumn{5}{|l|}{ Age } \\
\hline Age 27-29 & Reference & & Reference & \\
\hline Age $19-25$ & -0.09 & $(-0.23,0.05)$ & 0.11 & $(-0.10,0.32)$ \\
\hline
\end{tabular}


Table 4: Continued

\begin{tabular}{|c|c|c|c|c|}
\hline & \multicolumn{2}{|c|}{ Doctor Visit Cost } & \multicolumn{2}{|c|}{ ED Visit Cost } \\
\hline & Coef. & $95 \% C I$ & Coef. & $95 \% C I$ \\
\hline \multicolumn{5}{|l|}{ Year } \\
\hline Pre-ACA (year 2008-2009) & Reference & & Reference & \\
\hline Post-ACA (year 2011-2012) & -0.04 & $(-0.24,0.16)$ & 0.31 & $(0.10,0.53)^{* * *}$ \\
\hline \multicolumn{5}{|l|}{ 95th percentile } \\
\hline \multicolumn{5}{|l|}{ Interaction term } \\
\hline Age $19-25^{*}$ post-ACA & -0.28 & $(-0.58,0.02)$ & -0.30 & $(-0.69,0.08)$ \\
\hline \multicolumn{5}{|l|}{ Age } \\
\hline Age 27-29 & Reference & & Reference & \\
\hline Age 19-25 & -0.09 & $(-0.25,0.07)$ & 0.13 & $(-0.06,0.33)$ \\
\hline \multicolumn{5}{|l|}{ Year } \\
\hline Pre-ACA (year 2008-2009) & Reference & & Reference & \\
\hline Post-ACA (year 2011-2012) & 0.16 & $(-0.12,0.43)$ & 0.33 & $(-0.01,0.67)$ \\
\hline
\end{tabular}

Notes. ${ }^{* * *} p<.001 ; * * p<.01 ; * p<.05$. Regressions presented above control for predisposition factors (i.e., race/ethnicity, gender, marital status, and interview language) enabling factors (i.e., education, family income, urban/rural, and U.S. Census Region), and clinical need factors (i.e., self-reported physical, mental health, presence of major chronic disease). Full sets of results are presented in Appendix SA5.

\section{DISCUSSION}

Our results suggest that the ACA expansion of dependent coverage might have contributed to the controlled growth of health care expenditures among adults ages $19-25$ by extending insurance coverage to this population through employer-sponsored health coverage. Increased health insurance coverage could have contributed to stable health spending growth through the decline in catastrophic expenditures (such as expenditures on expensive health care services). Our results confirm previous conceptual frameworks that predict fewer OOP health expenditures and increased financial protection of newly insured populations as a consequence of expansionary health insurance policies (Xu et al. 2007; Mulcahy et al. 2013; Chua and Sommers 2014). Newly insured individuals are more likely to make a more efficient allocation of personal resources on health care expenditures. Our study also provides early evidence of reduced overall health care expenditures among young adults 1925 who were among the first beneficiaries of the ACA implementation.

Contrary to the assumption that most young adults are healthy, it is important to note that "one in six young adults has a chronic illness such as cancer, diabetes, or asthma" (Centers for Medicare \& Medicaid Services 2010). On average, young people are healthier and less likely to need health 
insurance compared with older adults. The health care needs of uninsured and vulnerable young adults, however, have often times been overlooked and underestimated. Multiple chronic conditions that in the past were primarily present among older adults such as diabetes and heart disease are becoming more common among young adults. In addition, younger populations are more likely to be involved in high-risk behaviors such as substance use.

Lack of health insurance in early adulthood could contribute to undetected or uncontrolled onset of chronic conditions, increasing the cost of treating chronic conditions in the future when young adults establish health insurance coverage through their employers or the government. Uninsured young populations may not have timely access to primary care and eventually end up in the ED, which is a more expensive setting for care. Thus, insurance coverage expansion for young adults has the potential to improve the efficiency of allocating financial resources for individuals and households and reduce the nationwide health care expenditures, as government spending on health care (through Medicare and Medicaid programs) is projected to increase in the coming decades (Holahan and McMorrow 2012).

Our analyses from a payer perspective did not show any significant differences between the timing of the ACA expansion of dependent coverage for young adults and expenditures of private health insurers. This suggests that the ACA expansion of dependent coverage was mainly associated with a shift in reported OOP cost and did not represent an additional cost to payers. From a policy perspective, our findings suggest that the ACA expansion of young adult eligibility for dependent coverage may not have represented additional costs for payers while it benefited households with previously uninsured young adults by reducing reported OOP costs. It is also worth noting that more years of observation may be needed to reflect the time lag. Future research should explore effects on payers since our categories are broad; it is also important to disaggregate payer effects by coverage types and geographic areas.

Results also show that young adults ages 19-25 had higher ED costs compared with the control group at the lower end of the distribution. This finding is consistent with the literature of the impact of health insurance coverage on ED visits (Smulowitz et al. 2014; Obamacare facts 2015). Increased spending on ED services among young adults with overall low expenditures may reflect the area where health insurance coverage might have been more beneficial for a population that on average is healthier than older adults. While health insurance coverage protected young adults from all types of 
unexpected health events, perhaps situations that led to ED utilization were the more widespread among this particular population.

In spite of the differences and possible improvement of the estimation, our study has some limitations. First, using a natural experiment event, we estimate treatment effects using repeated cross-sectional data and study design. Our results show the trend of expenditures before and after the ACA insurance expansion. Even though we use difference-in-differences estimation as well as GLM to estimate the causal effect between the ACA expansion and health care expenditures, our results cannot infer the precise causality given the data availability. It is possible that unobserved market effects, such as the Great Economic Recession and geographic variation, might confound our findings. A longitudinal data set would be needed to study the long-term impacts of the ACA coverage expansion on health care costs. Second, our study does not examine long-term health outcomes. Long-term health evaluations would be able to provide more robust evidence of the ACA's impact on population health. Third, we study the overall trend of health care expenditures, and we examine health care expenditures from the payer perspective to capture possible "cost shifting" that may happen under this ACA expansion. However, our payer measures are too broad for specific inferences given the heterogeneity in Medicaid across states and private insurance plan benefits.

\section{CONCLUSIONS}

Extended coverage eligibility from age 21 to age 26 under the ACA has increased financial protection for young adults. Our results show that this ACA provision significantly reduced overall health care expenditures among this target population. Meanwhile, our results suggest that enrollment into family private health insurance might have successfully reduced spending by reducing catastrophic expenditures and protecting the financial future of young adults from unexpected health events.

\section{ACKNOWLEDGMENTS}

Joint Acknowledgment/Disclosure Statement: Dr. Jie Chen acknowledges the support from the National Institute of Mental Health R21MH106813-01 and 
Agency for Healthcare Research and Quality R24 HS22135-01. Ms. Novak was an employee of the Agency for Healthcare Research and Quality at the time this research was conducted. The opinions expressed in this document are those of the authors and do not reflect the official position of AHRQ or the U.S. Department of Health and Human Services. Ms. Novak is a graduate student at University of Maryland-College Park.

Disclosures: None.

Disclaimers: None.

\section{REFERENCES}

Aday, L. A., and R. Andersen. 1974. "A Framework for the Study of Access to Medical Care." Health Services Research 9: 208-20.

Andersen, R. 1995. "Revisiting the Behavioral Model and Access to Medical Care: Does It Matter?" Journal of Health ES Social Behavior 36: 1-10.

Barbaresco, S., C. Courtemanche, and Y. Qi. 2015. "Impacts of the Affordable Care Act Dependent Coverage Provision on Health-Related Outcomes of Young Adults." Journal of Health Economics 40: 54-68.

Bertrand, M., E. Duflo, and S. Mullainathan. 2004. "How Much Should We Trust Differences-in-Differences Estimates?” The Quarterly Journal of Economics 119: 249-75.

Busch, S. H., E. Golberstein, and E. Meara. 2014. "ACA Dependent Coverage Provision Reduced High Out-of-Pocket Health Care Spending for Young Adults." Health Affairs (Millwood) 33: 1361-6.

Callahan, S. T., and W. O. Cooper. 2005. "Uninsurance and Health Care Access among Young Adults in the United States." Pediatrics 116: 88-95.

Cantor, J. C., A. C. Monheit, D. DeLia, and K. Lloyd. 2012a. "Early Impact of the Affordable Care Act on Health Insurance Coverage of Young Adults." Health Services Research 47: 1773-90.

Cantor, J. C., D. Belloff, A. C. Monheit, D. Delia, and M. Koller. 2012b. "Expanding Dependent Coverage for Young Adults: Lessons from State Initiatives.” Journal of Health Politics, Policy, and Law 37 (1): 99-128.

Centers for Medicare \& Medicaid Services. 2010. Young Adults and the Affordable Care Act: Protecting Young Adult and Eliminating Burdens On Families and Businesses. Washington, DC: Department of Health and Human Services.

Chen, J., A. Vargas-Bustamente, and A. N. Ortega. 2013. "Health Care Expenditures among Asian American Subgroups." Medical Care Research Review 70 (3): 310-29.

Chen, J., A. Vargas-Bustamante, K. Mortensen, and S. Thomas. 2014. "Using Quantile Regression to Examine Health Care Expenditures during the Great Recession." Health Services Research 49: 705-30.

Chua, K. P., and B. D. Sommers. 2014. "Changes in Health and Medical Spending among Young Adults under Health Reform." Journal of American Medical Association 311: 2437-9. 
Claxton, G., M. Rae, N. Panchal, A. Damico, H. Whitmore, N. Bostick, and K. Kenward. 2013. "Health Benefits in 2013: Moderate Premium Increases in Employer-Sponsored Plans." Health Affairs (Millwood) 32 (9): 1667-76.

Cohen, J. W., S. B. Cohen, and J. S. Banthin. 2009. "The Medical Expenditure Panel Survey: A National Information Resource to Support Health Care Cost Research and Inform Policy and Practice." Medical Care 47: S44-50.

Cook, B. L., and W. G. Manning. 2009. "Measuring Racial/Ethnic Disparities across the Distribution of Health Care Expenditures." Health Services Research 44: 1603-21.

Dimick, J. B., and A. M. Ryan. 2014. "Methods for Evaluating Changes in Health Care Policy: The Difference-in-Differences Approach." Journal of American Medical Association 22: 2401-2. doi:10.1001/jama.2014.16153.

Golberstein, E., S. Busch, R. Zaha, S. Greenfield, W. Beardslee, and E. Meara. 2015. "Effect of the Affordable Care Act's Young Adult Insurance Expansions on Hospital-Based Mental Health Care.” American Journal of Psychiatry 172: 182-9.

Goldberger, A. S. 1964. Econometric Theory. New York: John Wiley \& Sons.

Holahan, J., and S. McMorrow. 2012. "Medicare and Medicaid Spending Trends and the Deficit Debate." New England Journal of Medicine 367: 393-5.

Kaiser Commission on Medicaid and the Uninsured. 2014. "The Uninsured: An Interactive Tool." Washington, DC [accessed on September 1, 2014]. Available at http://kff.org/interactive/the-uninsured-an-interactive-tool/

Kaiser Family Foundation. 2013. "Employer Health Benefits: 2013 Annual Survey" [accessed on September 1, 2014]. Available at http://ehbs.kff.org/pdf/2011/ 8225.PDF

Koenker, R. 2005. Quantile Regression. Econometric Society Monograph Series. Cambridge, UK: Cambridge University Press.

Koenker, R., and K. F. Hallock. 2001. "Quantile Regression.” Journal of Economic Perspectives 15: 143-56.

$\mathrm{Ku}, \mathrm{L}$. 2009. "Health Insurance Coverage and Medical Expenditures of Immigrants and Native Born Citizens in the United States." American Journal of Public Health 99: 1322-8.

Manning, W. G., A. Basu, and J. Mullahy. 2005. "Generalized Modeling Approaches to Risk Adjustment of Skewed Outcomes Data." Journal of Health Economics 24: 465-88.

Merluzzi, T. V., and R. C. Nairn. 1999. "Adulthood and Aging: Transitions in Health and Health Cognition." In Life-Span Perspective on Health and Illness, edited by T. L. Whitman, T. V. Merluzzi, and R. D. White, pp. 189-206. Mahwah, NJ: Erlbaum.

Mulcahy, A., K. Harris, K. Finegold, A. Kellermann, L. Edelman, and B. D. Sommers. 2013. "Insurance Coverage of Emergency Care for Young Adults under Health Reform.” New England Journal of Medicine 368: 2105-12.

Obamacare Facts. 2015. "Study Shows ER Visits Up under ACA" [accessed on June 8, 2016]. Available at http://obamacarefacts.com/2015/05/05/study-shows-ervisits-up-under-aca/

Rhoades, R. 2015. "Health Insurance Status of Young Adults, Ages 19-25, 2013." Agency for Healthcare Research and Quality Website [accessed June 7, 2016]. 
Available at http://meps.ahrq.gov/mepsweb/data_files/publications/st475/ stat475.pdf

Smith, S. 2009. "CDC: Young Invincibles' Have Significant Health Concerns." CNN [accessed on September 1, 2014]. Available at http://www.cnn.com/2009/ HEALTH/02/17/cdc.young.people/

Smulowitz, P. B., J. O’Malley, X. Yang, and B. E. Landon. 2014. "Increased Use of the Emergency Department after Health Care Reform in Massachusetts." Annals of Emergency Medicine 64: 107-15.

Sommers, B. D., T. Buchmueller, S. L. Decker, C. Carey, and R. Kronick. 2013. "The Affordable Care Act Has Led to Significant Gains in Health Insurance and Access to Care for Young Adults." Health Affairs (Millwood) 32: 165-74.

Staton, M. W. 2006. "The High Concentration of U.S. Health Care Expenditures." Agency for Health care Research and Quality Website [accessed September 1, 2014]. Available at http://www.ahrq.gov/research/findings/factsheets/costs/ expriach/index.html

U.S. Department of Labor. 2014. "Young Adults and the Affordable Care Act: Protecting Young Adults and Eliminating Burdens on Families and Businesses" [accessed on September 1, 2014]. Available at http://www.dol.gov/ebsa/ newsroom/fsdependentcoverage.html

Ware, J. E., M. Kosinski, and S. D. Keller. 1996. "A 12-item Short-Form Health Survey: Construction of Scales and Preliminary Tests of Reliability and Validity." Medical Care 34: 220-33.

Wooldridge, J. 2002. Econometric Analysis of Cross Section and Panel Data. Cambridge, MA: MIT Press.

Xu, K., D. B. Evans, G. Carrin, A. M. Aguilar-Rivera, P. Musgrove, and T. Evans. 2007. "Protecting Households from Catastrophic Health Spending." Health Affairs (Millwood) 26: 972-83.

\section{SUPPORTING INFORMATION}

Additional supporting information may be found in the online version of this article:

Appendix SA1: Author Matrix.

Appendix SA2: Demonstration of Comparable Trends in Health Care Expenditures for Young Adults Ages 19-25 and Ages 27-29 Years Old from 2003 to 2009 (pre-ACA-dependent coverage expansion): Results of GLM Regression Results on Total Health Care Expenditures and Expenditures by Payer Type.

Appendix SA3: Demonstration of Comparable Trends of Health Care Expenditures for Young Adults Ages 19-25 and Ages 27-29 Years Old from 2003 to 2009 (pre-ACA-dependent coverage expansion): Results of GLM 
Regression Results on Different Types of Health Care Expenditures.

Appendix SA4: Full Results of the Quantile Regressions of Health Care Expenditures.

Appendix SA5: Full Results of the Quantile Regressions of Health Care Expenditures by Services. 